\title{
EL CASTELL MAJOR EN TEMPS DEL DIBUIXANT ANTON VAN DEN WYNGAERDE (1525-1571)
}

\author{
Pablo Camarasa Balaguer \\ Universitat de València
}

\begin{abstract}
Resumen: El present treball busca reconstruir gràficament, fent ús de noves ferramentes digitals, el castell major de Xàtiva prenent com a model el dibuix executat pel pintor flamenc Anton van den Wyngaerde, en un intent per, en base a un anàlisi formal i material, poder formular una proposta d'usos per als edificis que conformaven aquest conjunt fortificat.
\end{abstract}

Palabras clave: Xàtiva, arquitectura, història, reconstrucció.

The Major Castle in the time of the draftsman Anton van den Wyngaerde (1525-1571)

Abstract: The present work seeks to reconstruct graphically, making use of new digital tools, the mayor castle of Xàtiva taking as a model the drawing executed by the Flemish painter Anton van den Wyngaerde, in an attempt to, based on a formal and material analysis, be able to formulate a proposal of uses for the buildings that made up this fortified complex.

Key words: Xàtiva, architecture, history, reconstruction.

L'estructura de la fortalesa xativina, conformada per dos castells, guarda, tal i com ho corroboren els nombrosos estudis existents al voltant de la mateixa, una rica història.

El seu enclavament estratègic va fer del castell un dels recintes més importants de la Corona d'Aragó, arribant a convertir-se en presó d'estat des del segle XIII, i d'altra banda va afavorir a la ciutat des del punt de vista econòmic gràcies al seu control de les rutes comercials existents a les rodalies.

Estudiosos com Ventura Pascual i Beltrán i Carlos Sarthou primer, i investigadors com Agustí Ventura, Pedro López Elum i Juan Piqueras després, entre altres, han dut a terme treballs que han llançat llum sobre l'evolució del conjunt d'estructures recollides a l'interior del recinte fortificat objecte del present estudi.

A dits estudis serveix com a recolzament per al seu anàlisi la documentació gràfica existent. Aquesta no és molt nombrosa, doncs els plànols, vistes o di-

Data de recepció: 15 d'abril de 2020 / Data d'acceptació: 20 de maig de 2020. 
buixos (fins a l'aparició de la fotografia) són ben pocs. Es poden citar, des de l'el·laborada per Anton van den Wyngaerde l'any 1563 (i l'esbós que va dibuixar abans), fins a l'hipotètic plànol realitzat per Fra Tomàs Vicent Tosca a començaments del segle XVIII. A les vistes, a conseqüència de la seua representació des de la llunyania, la precisió amb respecte a la ubicació de cada edifici, és sempre aproximada, però a aquest respecte cal assenyalar una investigació realitzada per Julián Esteban Chapapría i Ricardo Sicluna Lletget centrada en l'estudi de la representació de Wyngaerde per a la ciutat de Xàtiva que va ser publicada baix el títol "La ciutat de Xàtiva i la seua arquitectura vista per Van den Wijngaerde" (Chapapria, Sicluna, 1990, pp. 259-301).

En el mateix llibre, que va estar coordinat per Vicenç Rosselló i Verger, també cal destacar el text el-laborat per Juan Piqueras "Xàtiva en el segle XVI. Assaig de geografia històrica a partir de Martí de Viciana i els dibuixos d'Anthoine van den Wijngaerde". Ambdós treballs són de gran utilitat per a obtenir una més ampla visió de la ciutat i el context que va trobar l'artista flamenc quan va rebre l'encàrrec de Felip II.

Altres vistes existents, encara que no tan descriptives com la citada anteriorment, van ser la realitzada per Palomino a mode de gravat l'any $1786 \mathrm{i}$ publicada al volum XI de l'Atlante Español de B. Espinalt. Es tracta d'una vista septentrional on, malgrat que destaca pel seu esquematisme, es pot distinguir el nucli central del castell major com a un conjunt de construccions o edificis que podrien vincular-se als representats temps enrere per Wyngaerde. També la vista realitzada per $\mathrm{H}$. Vilata, que com l'anterior és un gravat, i que es va realitzar a la mateixa centúria, representa la ciutat de Xàtiva des d'un punt de vista frontal. Tendeix cap a l'abstracció més encara que la darrera de Palomino, i representa un castell que s'extén per tot el cim de la muntanya on s'asenta. Aquesta podria ser considerada més com un dibuix romàntic de la ciutat que no com a font documental.

És coneguda una vista que es va executar durant la visita de Laborde i Moulinier a Xàtiva l'any 1806 i que va formar part de la seua publicació Voyage pittoresque et historique de l'Espagne. Aquesta es va centrar en la representació de la porta principal d'accés a la fortalesa, però, i encara que en segon pla, va incorporar també una vista única del castell major i les seues torres tal i com es trobava en aquells moments.

Una cuarta vista és la litografia realitzada per M. Bellver a mitjans del segle XIX partint d'una fotografia de Pasqual Pérez. Va estar citada per Vicent Boix al seu llibre Xàtiva. Memorias, recuerdos y tradiciones de esta antigua ciudad, i es tracta d'una recreació de la localitat que gaudeix d'un alt nivell de detall, però al tractar-se d'una obra creada després de 1748, el castell major es mostra ja en un estat de deteriorament avançat. 
I per altre costat cal destacar el relleu de la representació del castell situat a la porta lateral de la Seu dedicada a Santa Anastàsia. Situat per damunt de l'arc on es troben els símbols del martiri d'aquesta figura, és una de les representacions més valuoses per haver estat escolpida anys abans dels terratrèmols, doncs la construcció d'aquesta porta data de 1700, i mostra una gran quantitat d'edificis que s'alcen a mode de torres.

Respecte als plànols, després de la pèrdua de documentació sofrida a l'incendi de 1707, els que es poden consultar són posteriors a aquest succés. El primer d'ells on s'inclou la representació del castell és el treball realitzat per Antoine de Montaigú, qui, seguint l'obstinació del rei per alterar la morfologia urbana xativina, va ser reclamat per a que el·laborara un plànol amb noves aliniacions, buscant modificar carrers principals i la seua sinousitat per convertir-los en carrers rectes. Es tracta d'un document molt interessant ja que no s'ha localitzat cap plànol de nivell semblant de detall anterior a aquest, doncs Xàtiva manca d'una vista realitzada com a manifest arquitectònic.

Un altre plànol és el que va realitzar el capità enginyer Vallantin l'any 1812 mitjançant encàrrec de l'exèrcit francés durant la Guerra de la Independència amb la finalitat d'estudiar diferents enclaus estratègics que poguessin ser útils per a la batalla. L'original es troba a l'Arxiu Històric Militar de París i en aquest es va representar la ciutat de Xàtiva de manera esquemàtica i el castell més ben definit. Es tracta, per tant, d'un document valuós per poder deduïr quina era la planta, en aquest cas, del nucli principal del castell major. A més, el mateix ve acompanyat d'una sèrie de documents que es centren en la defensa de la ruta d'Alcoi, prestant especial atenció a la rehabilitació dels murs del castell.

Per a dur a terme l'anàlisi i interpretació del dibuix que Wyngaerde va efectuar del castell major, totes les fonts esmentades, en major o menor mesura, han estat d'utilitat. A totes aquestes cal afegir la representació de la planta actual, la qual permet situar els diferents elements representats pel flamenc en un espai concret.

Encara que no existeix una idea clara respecte a la finalitat que el rei Felip II volia atorgar a les vistes de Wyngaerde, es barallen hipòtesis tals com que es tractara d'un projecte que acabara sent una mena d'atlas de ciutats espanyoles (Kagan, 1986, p. 41), que s'encarregaren per a l'enaltiment d'aquestes o simplement que el monarca les utilitzara per al seu goig personal. De fet, i malgrat que aquestes representacions no van ser molt difoses al seu moment, Felip II va ordenar que es penjaren de les parets dels corredors d'alguns dels seus palaus per tal que totes aquelles persones que els visitaren, pogueren gaudir-les (Kagan, 2009, p. 98).

Va ser l'any 1561 quan Felip II va reclamar la presència d'Anton van der Wyngaerde a Madrid. Abans d'allò, el rei havia visitat Anglaterra, i tal volta enllà va ser on va conéixer l'obra i, concretament les vistes de ciutats, realitzades 
per aquest artista. Una vegada instal-lat a Espanya, va començar a treballar per a la cort, sent nomenat pintor de càmera i rebent l'encàrrec de viatjar per diferents indrets de la geografia ibèrica per tal d'obtindre vistes topogràfiques d'unes seixanta-dues ciutats del regne.

Els dibuixos realitzats per Wyngaerde per a Xàtiva no són els més precisos de tots aquells que va dur a terme, encara que en allò que es refereix al castell, sí són d'utilitat per poder distingir alguns dels volums, si no tots, que donaven forma a aqueixa fortalesa. Respecte al castell major, i concretament a l'espai comprés entre la tercera i la quarta porta del mateix i la coneguda com a torre de la $\mathrm{Fe}$, que tanca la fortificació per l'oest, tant a l'esbós, com al dibuix definitiu, s'inclouen un número de cossos coincident.

A aquest respecte, cal assenyalar que el present estudi es basa en la interpretació del dibuix de Wyngaerde, i encara que pretén esclarir la forma d'alguns dels volums que conformaven el castell major, no deixa de ser una reconstrucció que atén, per damunt de qualsevol font escrita, a la vista del flamenc.

Així, i quant als edificis representats, el primer que cal destacar és la torre de la Fe. Es tracta d'una construcció de planta lleugerament rectangular, situada com s'ha dit anteriorment a la part més occidental de la fortalesa. La seua alçària podria arribar fins als 12 metres, atenent a les representacions existents de la mateixa. Al seu dibuix, Wyngaerde mostra un cos que s'alça convertintse en el punt més elevat de la fortalesa. Atenent a aquest, es distingeixen diferents nivells. Si u es fixa en les finestres, es poden identificar fins a quatre.

Una característica destacable en aquest cas és el tram superior. El flamenc va representar un volum amb una superfície major proporcionada per un forjat volat a mode de matacà. És ressenyable principalment perquè no hi ha cap altra vista o representació on s'aprecie la seua existència, i de fet, a l'esbós, del mateix Wyngaerde es mostra una construcció de coberta plana. Tampoc al relleu situat sobre la porta lateral de la Seu dedicada a Santa Anastàsia s'hi veu una torre com aquesta.

La documentació existent recolza la idea de que es tractara d'un intent d'embelliment per part de l'autor de la vista, doncs hi ha constància escrita d'una coberta plana, on s'encenien alimares ${ }^{1}$. Aquest document data de l'any 1461, així que la torre es remunta, al menys, al segle XV. A la centúria del 1500 es va reformar, o més bé reconstruir, però aquesta intervenció, encara que haguera estat inspirada en models italianitzants, no va poder estar representada per Wyngaerde perque es va començar l'any 1563 -un any després de la seua visita- a conseqüència d'un llamp que va fer esclatar el polvorí situat a l'interior de l'edifici (Ventura, 1998, p. 275).

\footnotetext{
1 ARV 9296, fol. 45.
} 

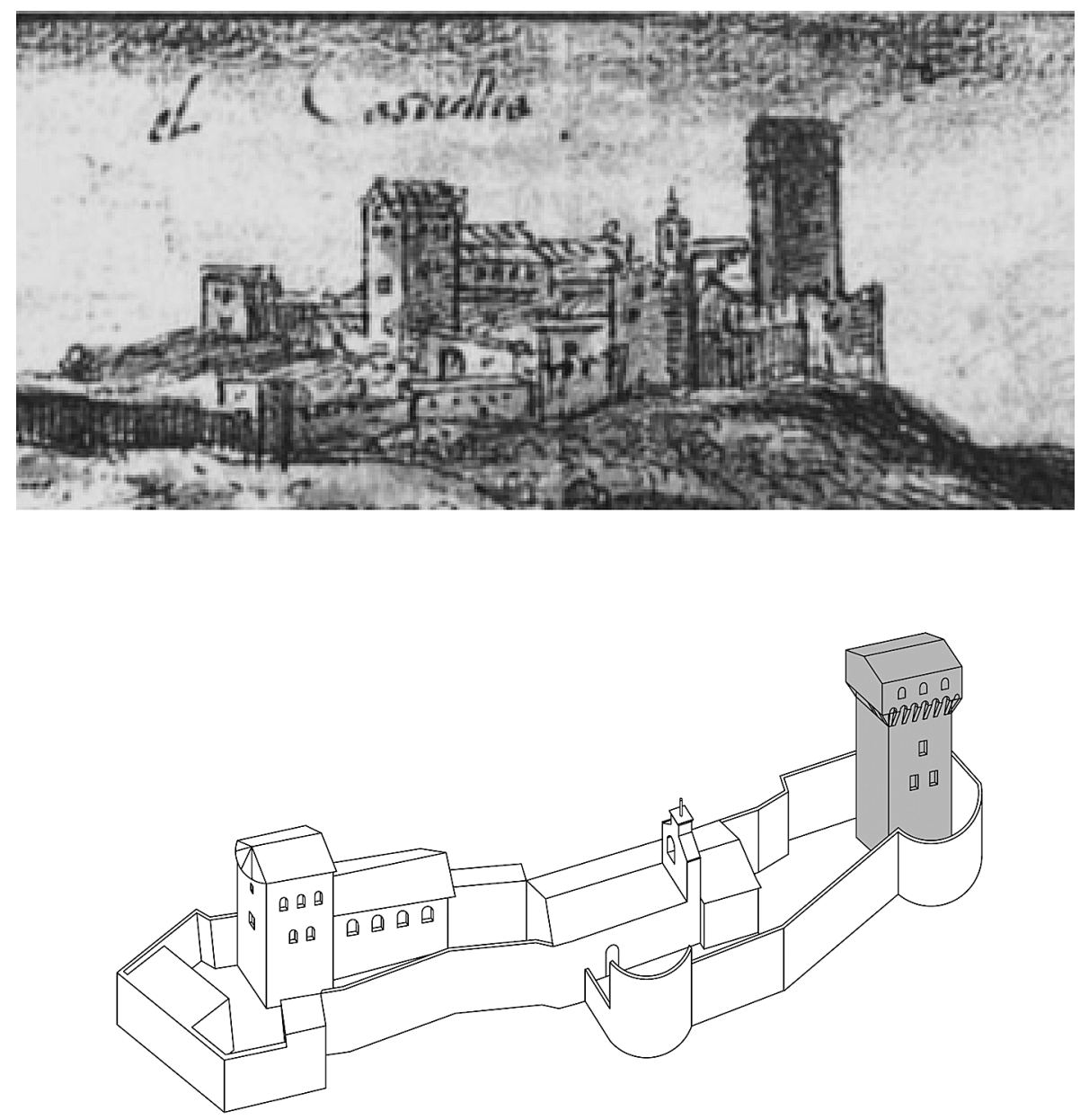

Fig. 1. (Dalt) Detall del dibuix de Wyngaerde. (Baix) Vista recreada per l'autor del text. En gris, i en ambdós casos, torre de la Fe.

El representat, com s'ha adelantat, es tracta d'un tipus constructiu italianitzant, concretament de la zona de Toscana, molt poc comú al territori valencià $^{2}-$ a excepció de les torres de Gilet i Benavites, o les del palau dels comtes

${ }^{2}$ Si s'estudien els 104 castells o fortaleses de la província de València declarades BIC i indexades a l'Inventari General de Patrimoni Cultural Valencià, es pot veure que únicament dues d'aquestes esmentades responen a aquesta tipologia italianitzant, cosa que suposa un 1 ' $92 \%$ del total. 
de Cocentaina, encara que aquestes varien, doncs el matacà és molt discret. Aquesta escassetat com a dada, s'afegeix a les idees anteriorment esmentades per justificar que el disseny representat no es correspondria amb la realitat.

El segon edifici o conjunt d'edificis representats correspon a la coneguda com a torre de Sant Jordi i un volum annex a aquesta per la seua façana oest. La torre contava amb una planta més -tres- que el cos amb que allindava -dues-. Front a aquest s'obria un espai on en un punt concret es conserva encara hui paviment que respon al tipus d'opus spicatum, i que es remuntaria a època romana. L'espai obert s'utilitzaria com a plaça, on es trobarien accessos als altres volums, i on puntualment s'ajusticiaria als presoners. Wyngaerde es va fer resò d'aquesta pràctica al seu esbós, on va assenyalar que, precisament a aqueix espai, es va degollar a l'assassí del germà del comanador de Montesa, en Dídac de Borja.

I es produïen precisament enllà per que la presó, o una part de la mateixa, es trobava a la torre de Sant Jordi i l'edifici annex. Així, aquest segon cos més baix restaria íntegrament destinat per a cel·les, les quals serien, atenent a les finestres i pensant en l'existència d'un vestíbul per a la guàrdia, tres en cada nivell. Documentació escrita ho ratifica: "Item en la presó que està enfront de la plaça d'armes, que cau a Bixquert s'ha de posar una biga de vint pams poc més o menys de galga de sis" (Recollit per Ventura, 1998, p. 270, tret d'ARV D.B. 312, fol. 836). També fonts escrites registren l'existència d'una cavallerissa i, seguint aquestes, a la primera planta l'estada no estaria compartimentada, sinó que seria diàfana (on s'allotjaria el duc de Calàbria).

Ambdós volums estaven comunicats mitjançant una porta-com es reflecteix al plànol el·laborat per Vallantin-, i a l'interior de la torre també hi es van destinar estades com a masmorres. Un document de l'any 1665 assenyala que "en la presó del quarto de la Torre de Sant Jordi s'ha de fer una finestra" (Recollit per Ventura, 1998, p. 267, tret d'ARV DP. 301, fol. 631).

L'edifici de la presó es tancava amb una coberta a dues aigües amb orientació nord-sud. La torre de Sant Jordi, segons el dibuix del flamenc, també gaudia d'una coberta d'aquest tipus, encara que a l'est es distingeix una mena de voladís que podria ser una prolongació de la coberta o el ràfol de la coberta sud, visible degut al punt de vista des d'on es duia a terme la representació.

Aquesta façana est enfronta amb la capella coneguda com de Santa Maria, i, si bé la torre es situa entre la tercera i quarta porta del castell major, Wyngaerde la col-loca adherida al tram de mur on es troba una porta que podria ser aqueixa tercera, restant un tant allunyada d'un cos que deu correspondre a dita capella. Molt probablement el pintor va cometre aquesta errada per la distància, malgrat que abans d'executar el treball havia visitat el castell per obtindre major coneixement del mateix i prendre dades d'espais concrets, com després va reflectir a l'esbós. 

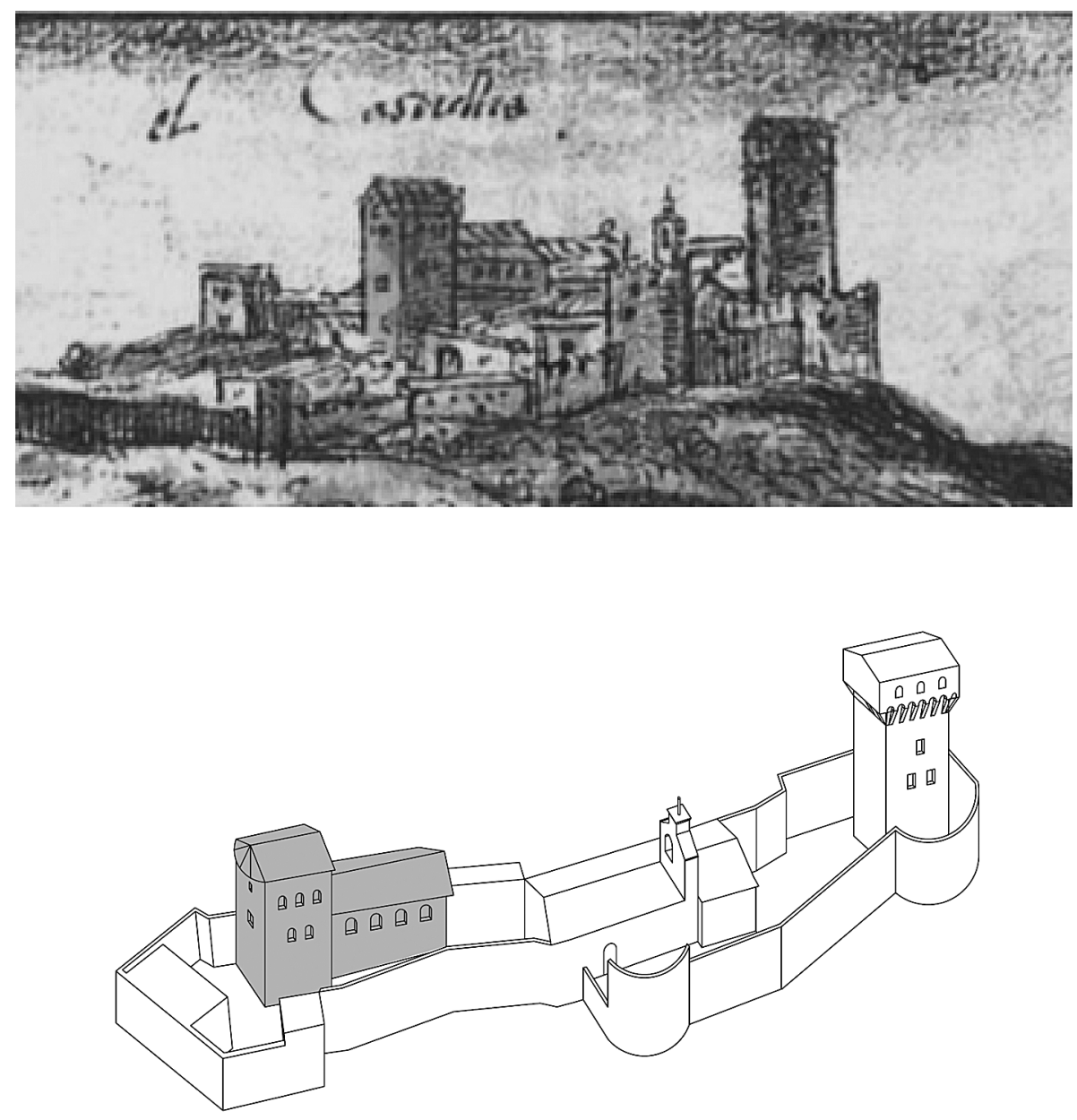

Fig. 2. (Dalt) Detall del dibuix de Wyngaerde. (Baix) Vista recreada per l'autor del text. En gris, i en ambdós casos, torre de Sant Jordi i edifici de la presó.

Un tercer conjunt de volums identificats al dibuix de Wyngaerde es situen en primer plànol, al centre de la representació, restant per darrere d'una torre de planta semicircular que correspon a la torre de la campana. El dibuix permet esclarir, en primer lloc, el motiu del nom de l'esmentada torre, doncs per damunt de la mateixa es distingeix una espadanya on es trobava la campana del castell major, utilitzada tant per motius militars -com avís en cas de perill-, com agrícoles - per avisar dels torns de reg-. El tram de mur que s'ubica a la seua dreta i 
que enllaça amb la torre situada per davant de la dita de la Fe degué sofrir una intervenció amb la finalitat d'augmentar la seua altura amb posterioritat, ja que en l'actualitat l'alçària d'aquesta és major que la terminació de les dues torres citades. A la vegada, i sempre analitzant la representació en qüestió, la torre redona degué perdre altura fins adquirir les dimensions contemporànies.

En la planta inferior, la situada a la mateixa cota de l'espai exterior, encara hui resten en peu dos espais, essent u d'ells identificat com la presó fosca i l'altre l'avantsala d'aquesta. Al costat es situa el pou o aljub i a l'altra banda d'aquest, al costat d'on hui es troben les escales per accedir a la planta superior, devia situar-se una altra masmorra, doncs hi ha constància escrita de l'existència de dos cel·les en aquest lloc al voltant del pou.

Atenent a les restes actuals que delimiten la planta, o part de la mateixa, $\mathrm{i}$ suposant l'existència d'una porta oberta cap a l'est, donant a la plaça d'armes, s'intueix un primer espai tancat només atravessar aquesta a la dreta, abans d'arribar a l'actual accés cap a la presó fosca. El pas del temps i el deteriorament no permeten apreciar els límits de la resta d'estades d'aquest nivell, però sabent que hi havia una sala vella i una d'altra nova per al duc, molt probablement la vella es situaria dins d'aquestos murs.

Per damunt s'alçava altre nivell, actualment desaparegut, el qual s'intueix pel buit d'una porta de mig punt i una finestra de corbes reconstruïda al segle XX, on tradicionalment s'ha situat la sala vella del duc. Si bé determinades fonts escrites assenyalen que aquesta es trobaria en eixe espai concret, altres indiquen que sobre la sala vella del duc hi havia un altre nivell on es situava l'estada de l'alcaid o comandant. Si es contrasta aquesta informació amb la representació de Wyngaerde, i la posició de la finestra, es pot apreciar que el volum referit sols contava amb planta baixa i primer nivell. A més, per accedir a la sala del primer pis calia travessar primer la sala on hi estaven els guàrdies encarregats de la campana, entre altres tasques, cosa que convida a pensar que també, i en cas que l'estada de l'alcaid estiguera en el primer nivell, complirien funcions de vigilància i protecció de la figura més important al càrrec del castell. La manufactura de la pròpia finestra -hui en part reconstruida- és altra característica ressenyable, doncs cap altre element de la fortalesa presenta una major qualitat, i aquesta podria haver estat dissenyada per embellir la dependència de la màxima autoritat que, en nombroses ocasions havia estat un membre de la noblesa xativina, com els Fenollet o els Joan, acostumat a arquitectures de gran bellesa. Amb aquestes hipòtesis, la localització de la sala vella del duc es torna discutible.

Respecte a dita finestra, és significatiu el fet que Wyngaerde represente determinats elements buscant l'enaltiment de la bellesa i una finestra com aqueixa no arribara a incloure-la a la seua vista. Si bé per un costat aquest fet pot ser conseqüència de la distància, ja que sí apareix un buit a un lloc coincident amb 

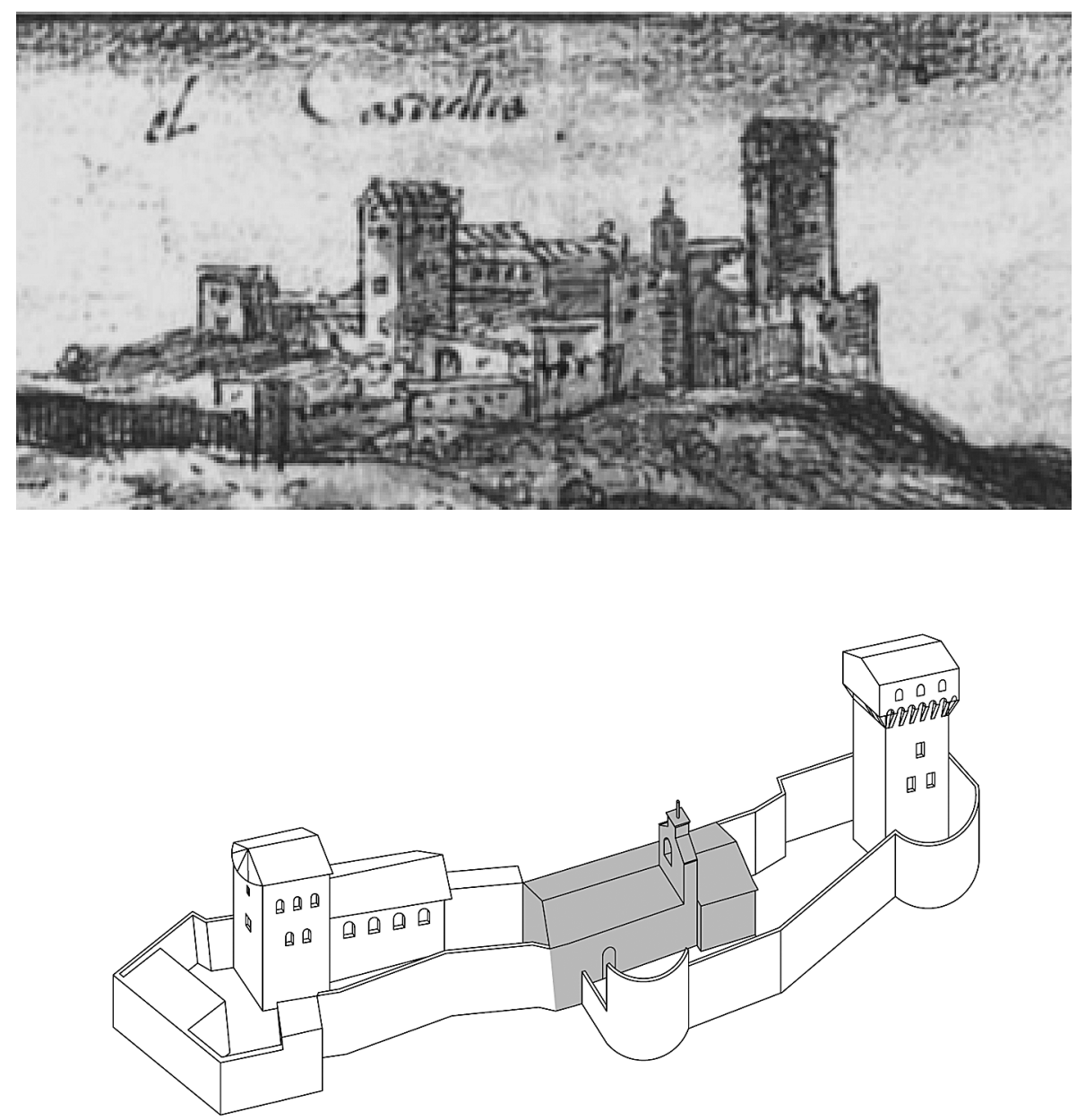

Fig. 3. (Dalt) Detall del dibuix de Wyngaerde. (Baix) Vista recreada per l'autor del text. En gris, i en ambdós casos, cos central amb diferents dependències.

la posició de l'esmentada, cal dir que a altres vistes, com la de Barcelona, Monzón, València o Saragossa, entre altres, es reconeixen diferents tipus de finestres o finestrals. A més, al cas particular de Xàtiva pareixen distingir-se finestres de corbes a la que llavors era la Casa de la Ciutat o a edificis situats a un carrer que correspon amb el de Corretgeria. Per a la representació d'aquestes, el flamenc dibuixava dues línies paral·leles. Al castell ho va fer dibuixant formes quadrades o rectangulars. 
Un quart i últim cos és aquell que serveix com a nexe d'unió entre l'edifici de la presó i l'últim conjunt citat. Segons el plànol del francés Vallantin es tractava d'un cos comunicat interiorment amb la presó, que contava a més amb una porta oberta cap a la plaça d'armes i allindava amb l'edifici central on es trobava l'estada de l'alcaid, dels guàrdies, les masmorres esmentades, la sala vella del duc i la campana.

Atenent a aquest document i encaixant la seua posició sobre la planta actual, devia situar-se adherit a part de la façana oest de la presó, encara que l'espai existent hui és de reduïdes dimensions. També podria correspondre amb l'espai que hui es vincula amb l'estada de l'alcaid i els guàrdies, orientada cap a la vall de Bixquert i de la que únicament resten les doveles de dos arcs apuntats en peu. Aquesta ubicació suposaria que l'edifici en qüestió es situaria, també, per darrere del conjunt central, malgrat que a les restes de la planta actual s'aprecia una distància no reflectida al plànol de Wyngaerde. A més, estant en aquesta ubicació, des d'on es va instal-lar per realitzar l'obra no el veuria.

En aquesta línia, cal assenyalar que no es tracta d'una representació gràfica de caràcter tècnic, sinó informatiu o ornamental. Per això, la posició dels diferents volums que composaven el castell major, i la distància entre ells, no és la correcta. Aquest fet s'aprecia tant en la separació entre la capella de Santa Maria i la torre de Sant Jordi, com en l'edifici en qüestió. També entre l'espai existent entre la torre de la $\mathrm{Fe}$ i el conjunt central.

Finalment, atenent a la materialitat, i sabent de les diverses i nombroses intervencions produïdes al llarg del temps, caldria destacar dos tipus constructius: un primer executat amb maçoneria i argamassa, $i$ un segon en el que destaca l'ús de la pedra treballada, a mode de carreus.

L'utilització d'unes tècniques o altres podria, per un costat, respondre a la importància atorgada als edificis i els seus usuaris, com per exemple la maçoneria per a la presó, tal i com queda reflectit en un document referent a tasques de rehabilitació conservat a l'Arxiu del Regne de València i on s'indica que “[...] De la sisa s'ha de trespolar la presó d'algeps i arena de tres dits de gruixa i s'ha de tapar un forat que hi ha en dit trespol d'argamassa i pedra, 20 lliures"3. Per altre costat, la tècnica constructiva també pareix respondre a motius estructurals, emprant-se la pedra en basaments com reflexa la torre de Sant Jordi o el volum central, on al menys fins al primer nivell tota la construcció es degué erigir amb carreus.

Respecte als artífexs, al moment en que es va produir la visita de l'artista a Xàtiva, diferents membres de la família dels Casanova, vinculada als oficis

\footnotetext{
${ }^{3}$ ARV DB 312, fol. 386, tret de Ventura, 1998, p. 270.
} 

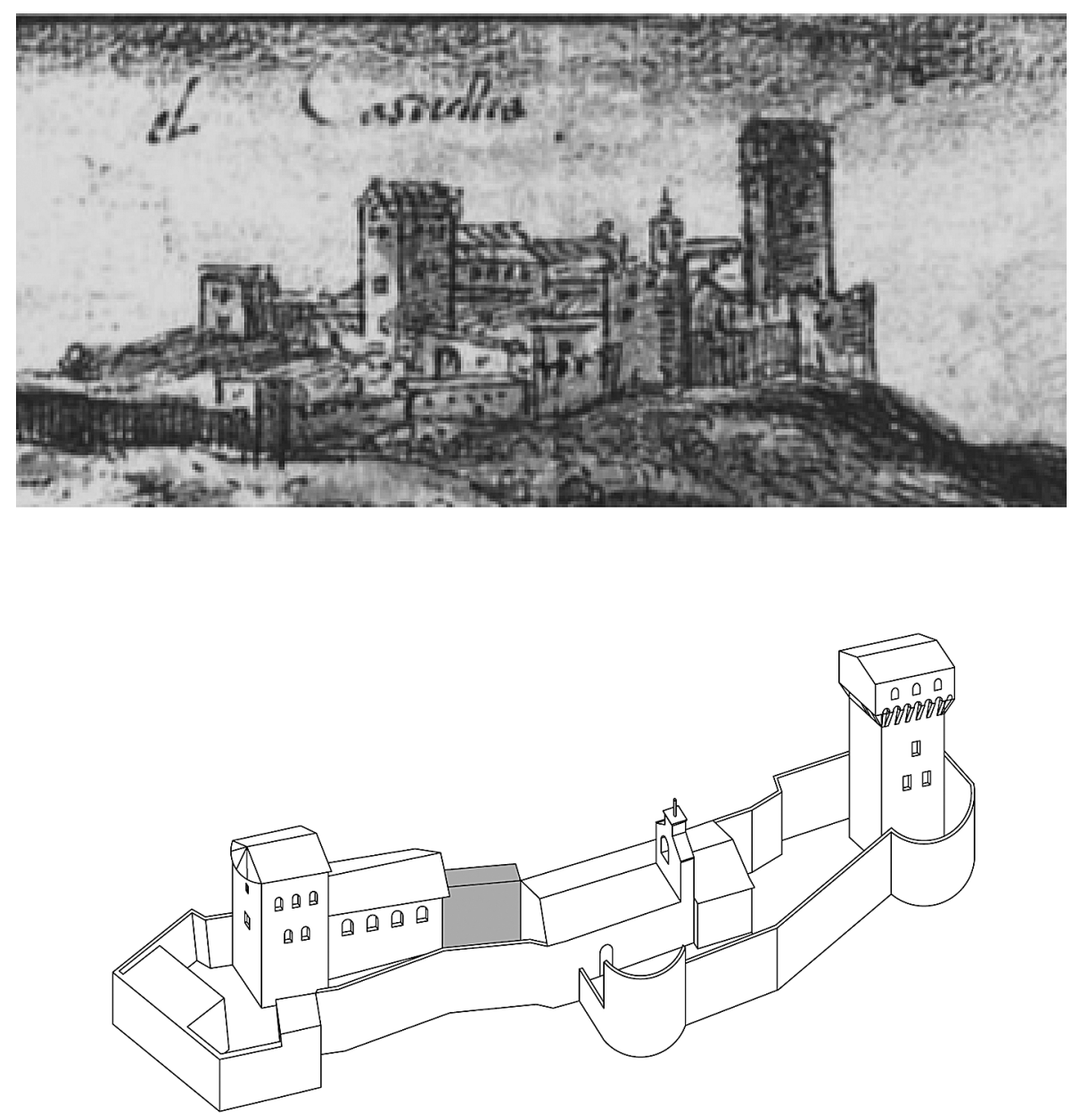

Fig. 4. (Dalt) Detall del dibuix de Wyngaerde. (Baix) Vista recreada per l'autor del text. En gris, i en ambdós casos, cos central amb diferents dependències.

de la construcció, venien ocupant el càrrec de mestre d'obres del castell. Alguns d'aquestos van ser Bertomeu Casanova el Major, Bertomeu Casanova el Menor, Lluís Casanova i Francesc Casanova (Camarasa, 2017, p. 233).

Si s'atén a la representació de Wyngaerde podria afirmar-se que al menys un dels edificis del castell major es va construir -o remodelar- en aquesta centúria, mentre que si s'analitza la seua arquitectura s'aprecien elements del XVI. 
Així, es pot afirmar que els Casanova van contribuir a la configuració del castell major que l'any 1562 va plasmar el flamenc.

A mode de conclusió, la configuració del castell major representat per Wyngaerde seria la d'una torre de la Fe emprada com a element defensiu -i probablement també com a presó-, una torre de Sant Jordi i un cos annex que s'utilitzarien, a banda de per a la defensa del castell, com a presó principalment; un conjunt central on es situaria la sala de l'alcaid, un espai per a la guàrdia i també cel·les, destacant la sala vella del duc de Calàbria, de localització dubtosa, i un últim volum que tancaria la composició per la part sud, de reduïdes dimensions i que tal vegada servira com a cavallerissa o espai de transició.

\section{BIBLIOGRAFIA}

CAMARASA BALAGUER, P. (2017): Arquitectura civil privada en Xàtiva. Siglos XIII$X I X$, València, Universitat de València, $322 \mathrm{p}$.

CARRASCO, E. F. (1748): Relacion puntual, circunstanciada de la ruinas, y extragos causados por los terremotos, que se sintieron en varias partes del Reyno de Valencia, los dias 23 de marzo, y 2 de abril de 1748, Valencia, Imprenta de la viuda de Antonio Bordazar, $118 \mathrm{p}$.

ESTEBAN CHAPAPRIA, J., SICLUNA LLETGET, R. (1990): "La ciutat de Xàtiva i la seua arquitectura vista per van den Wijngaerde" en: ROSSELLÓ VERGER, V. M. Les vistes valencianes d'Anton van den Wijngaerde, València, Ajuntament de València, 259-301.

FURIÓ, A. (2001): Història del País Valencià, València, Tres i Quatre, 664 p.

GARCÍA MARSILLA, J. V. (1997): "El mantenimiento de los recintos fortificados en la Valencia bajomedieval. Las reparaciones del castillo de Xátiva (1410-1412)", en: Acta historica et archaeologica mediaevalia, $\mathrm{n}^{\circ} 18,475-493$.

GÓMEZ-FERRER, M., ZARAGOZÁ, A. (2009) “Lenguajes, fábricas y oficios en la arquitectura valenciana del tránsito entre la Edad Media y la Edad Moderna (14501550)", en: ÁLVARO ZAMORA, M. I., IBÁÑEZ FERNÁNDEZ, J. La arquitectura en la Corona de Aragón entre el Gótico y el Renacimiento (1450-1550). Rasgos de unidad y diversidad, Tarazona, Fundación Tarazona, 149-184.

GONZÁLEZ AVILÉS, Á. B. (Ed.) (2017), Defensive architecture of the Mediterranean. XV to XVII centuries, Alicante, Universitat d'Alacant, $518 \mathrm{p}$.

KAGAN, R. L. (Dir.) (1986), Ciudades del Siglo de Oro. Las vistas de Anton Van den Wyngaerde, Madrid, El Viso, 356.

KAGAN, R. L. (2009), "Felipe II y el arte de la representación de paisajes urbanos", en: Anuario IEHS, 24, pp. 95-110.

LÓPEZ ELUM, P. (1982), "La geografia en la Crònica de Jaume I: els setges al castell i a la ciutat de Xàtiva", en: Papers de La Costera, 7-8, pp. 13-24.

LÓPEZ ELUM, P. (1989), "El castillo de Xàtiva desde la perspectiva de un estudio archivístico-arqueológico", en: Llibre de la Fira d'Agost, pp. 73-76. 
LÓPEZ ELUM, P. (2002), Los castillos valencianos en la Edad Media (materiales y técnicas constructivas), Valencia, Biblioteca Valenciana, vol. 1: 279 p., vol. 2: 256 p.

PASCUAL Y BELTRÁN, V. (1931), Játiva biográfica, València, Renovación Tipográfica.

PIQUERAS, J. (1990), “Xàtiva en el segle XVI. Assaig de geografia històrica a partir dels escrits de Martí de Viciana i els dibuixos d'Anthoine van der Wijngaerde", en: ROSSELLÓ VERGER, V. M. Les vistes valencianes d'Anton van den Wijngaerde, València, Ajuntament de València, pp. 221-258.

SARTHOU CARRERES, C. (1933-1935), Datos para la historia de Játiva, Xàtiva, Imprenta Blai Bellver, $170 \mathrm{p}$.

SARTHOU CARRERES, C. (1922), Los terremotos de 1748. Un capítulo para la historia de Játiva. Xàtiva, Impremta Enrique Bellver, 77 p.

TEROL i REIG, V. (ed.) (2006), Índex general de consells i actes de l'Arxiu Municipal de Xàtiva (1500-1550), València, Universitat de València, 309 p.

VELASCO BERZOSA, Á. (1995), "El sistema medieval defensiu de Xàtiva”, en: Llibret explicatiu de la falla Ferroviària, pp. 85-88.

VENTURA CONEJERO, A. (1998), El castell de Xàtiva, València, Matéu Impresores, 289 p. 
